\title{
Anaplasma phagocytophilum in the highly endangered Père David's deer Elaphurus davidianus
}

\author{
Yi Yang ${ }^{1,3}$, Zhangping Yang ${ }^{2,3^{*}}$, Patrick Kelly ${ }^{4}$, Jing Li ${ }^{1}$, Yijun Ren ${ }^{5}$ and Chengming Wang ${ }^{1,6^{*}}$ (D
}

\begin{abstract}
Eighteen of 43 (41.8\%) Père David's deer from Dafeng Elk National Natural Reserve, China, were positive for Anaplasma phagocytophilum based on real-time FRET-PCR and species-specific PCRs targeting the $16 \mathrm{~S}$ rRNA or msp4. To our knowledge this is the first report of $A$. phagocytophilum in this endangered animal.
\end{abstract}

Keywords: Anaplasma phagocytophilum, Père David's deer, Elaphurus davidianus, China

\section{Letter to the Editor}

Père David's deer (Elaphurus davidianus) are now found only in captivity although they occurred widely in northeastern and east-central China until they became extinct in the wild in the late nineteenth century [1]. In the 1980s, 77 Père David's deer were reintroduced back into China from Europe. Currently the estimated total population of Père David's deer in the world is approximately 5000 animals, the majority living in England and China. In China $40 \%$ of the animals are concentrated in the Dafeng Elk National Natural Reserve (DENNR) which attracts over one million tourists annually.

Anaplasma spp. are tick-transmitted obligate intracellular Gram-negative bacteria that cause a variety of animal diseases and can also infect people [2,3]. While control of ticks on domestic animals is time-consuming and costly, it is technically very difficult in wild animals and ticks are very common in the DENNR [4]. As Anaplasma infections cause considerable morbidity in animals in China [3], we tested 43 (20 males, 23 females) apparently healthy Père David's deer for infections with Anaplasma spp.

DNA was extracted from whole blood samples collected from the animals with the Roche High Pure PCR Template Preparation Kit (Roche Diagnostics

\footnotetext{
* Correspondence: yzp@yzu.edu.cn; wangche@auburn.edu

${ }^{2}$ Yangzhou University College of Animal Science and Technology, Yangzhou, Jiangsu, China

${ }^{1}$ Jiangsu Co-innovation Center for the Prevention and Control of Important Animal Infectious Diseases and Zoonoses, Yangzhou University College of Veterinary Medicine, Yangzhou, Jiangsu, China

Full list of author information is available at the end of the article
}

GmbH, Mannheim, Germany). The fluorescence resonance energy transfer (FRET) quantitative PCR targeting the $16 S$ rRNA gene of Anaplasma spp. [5] gave positive reactions for 18 deer (41.8\%), including 8 females (34.8\%) and 10 males (50.0\%). To investigate the species of Anaplasma present, the positive samples were further analyzed with species-specific primers targeting the $16 \mathrm{~S}$ rRNA gene of $A$. centrale, A. bovis, A. phagocytophilum and $A$. platys [6, 7] as well as the msp4 gene of $A$. marginale and A. ovis as described [8] (Table 1). All of the 18 positive samples were positive for $A$. phagocytophilum species-specific primers and sequencing of the PCR products with forward and reverse primers (BGI, Shanghai, China) and assembling using DNASTAR 7 revealed two different $A$. phagocytophilum $16 S$ rRNA fragment sequences.

Representative sequences identified in our study (MF470200 and M470201) were aligned using CLUSTAL W in MEGA 7 with those of 14 A. phagocytophilum and sequences for A. platys, A. bovis, A. marginale, A. centrale, A. ovis, Ehrlichia ruminantium, Ehrlichia chaffeensis and Ehrlichia muris retrieved from GenBank (Fig. 1). Phylogenetic analysis demonstrated that the Anaplasma isolates studied were all closely related to $A$. phagocytophilum based on the $16 S$ rRNA gene sequences (99.2-100\% similarity, 598-600 nucleotides). Compared with those of other Anaplasma spp., the similarity was $99.0 \%$ with $A$. platys (6 mismatches/599 nucleotides), $96.7 \%$ with $A$. bovis (20 mismatches/599_ 600 nucleotides), $97.2 \%$ with $A$. marginale (16 or 17 
Table 1 Oligonucleotide sequences of the primers used in this study

\begin{tabular}{|c|c|c|c|c|c|}
\hline \multirow[t]{2}{*}{ Pathogen } & \multirow[t]{2}{*}{ Target gene } & \multicolumn{2}{|l|}{ Primer } & \multirow[t]{2}{*}{ Amplicon size (bp) } & \multirow[t]{2}{*}{ References } \\
\hline & & Primer Name & Oligonucleotide sequence $\left(5^{\prime}-3^{\prime}\right)$ & & \\
\hline \multirow[t]{2}{*}{ A. centrale } & 165 rRNA & AC1f & CTGCTITAATACTGCAGGACTA & 426 & Kawahara et al., [6] \\
\hline & & $\mathrm{AC} 1 \mathrm{r}$ & ATGCAGCACCTGTGTGAGGT & & \\
\hline \multirow[t]{2}{*}{ A. bovis } & 165 rRNA & $A B 1 f$ & CTCGTAGCTTGCTATGAGAAC & 551 & Kawahara et al., [6] \\
\hline & & $A B 1 r$ & TCTCCCGGACTCCAGTCTG & & \\
\hline \multirow[t]{2}{*}{ A. phagocytophilum } & 165 rRNA & SSAP2f & GCTGAATGTGGGGATAATTTAT & 641 & Kawahara et al., [6] \\
\hline & & SSAP2r & ATGGCTGCTTCCTTCGGTTA & & \\
\hline \multirow[t]{2}{*}{ A. marginale } & msp4 & Amargmsp4 F & CTGAAGGGGGAGTAATGGG & 344 & Torina et al., [8] \\
\hline & & Amargmsp4 R & GGTAATAGCTGCCAGAGATTCC & & \\
\hline \multirow[t]{2}{*}{ A. ovis } & msp4 & Aovismsp4 F & TGAAGGGAGCGGGGTCATGGG & 347 & Torina et al., [8] \\
\hline & & Aovismsp4 R & GAGTAATTGCAGCCAGGGACTCT & & \\
\hline \multirow[t]{2}{*}{ A. platys } & 165 rRNA & Platys-F & AAGTCGAACGGATTTTTGTC & 504 & Inokuma et al., [7] \\
\hline & & Platys-R & CTTAACTTACCGAACC & & \\
\hline
\end{tabular}

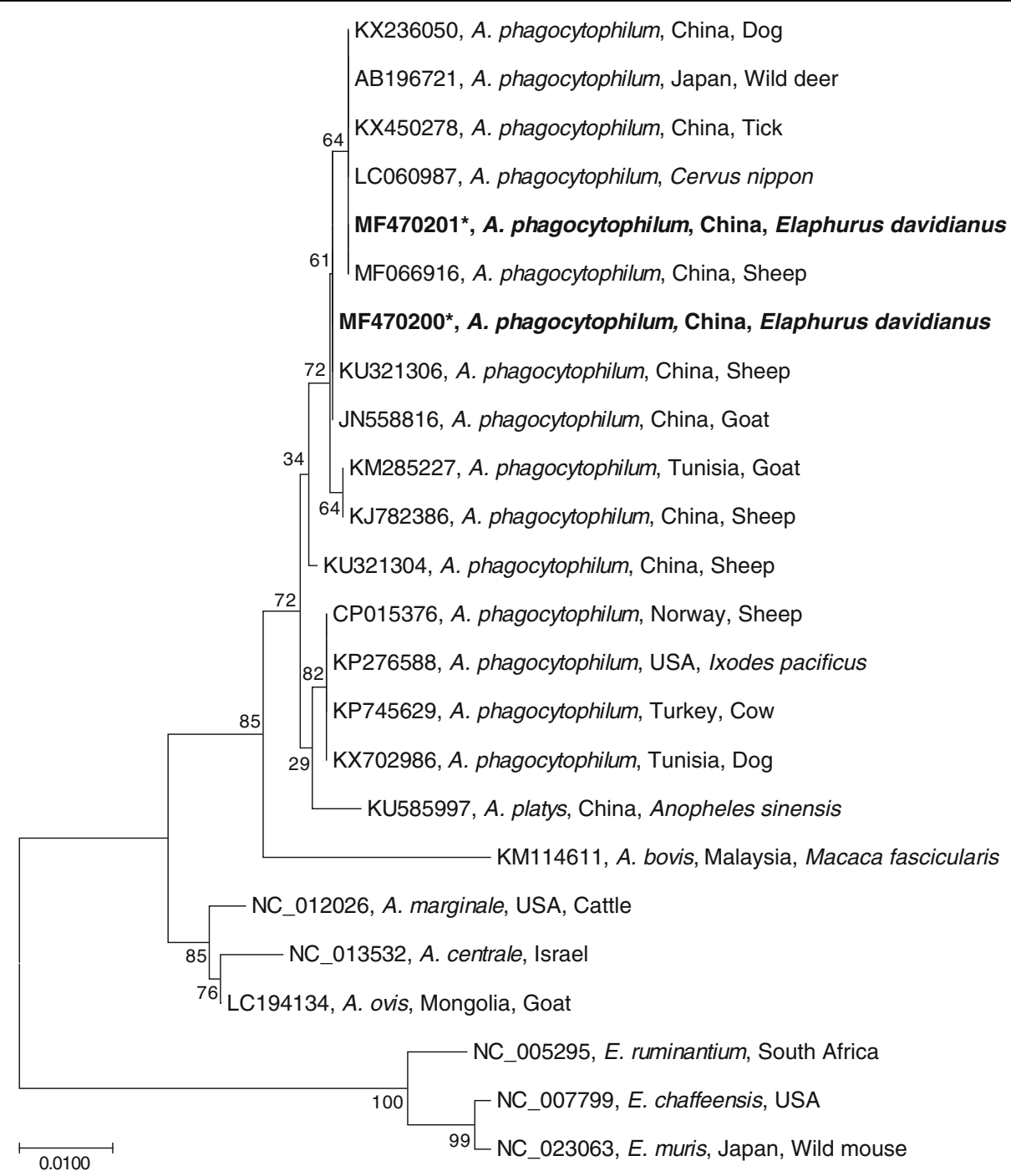

Fig. 1 Neighbor-joining phylogenetic tree based on sequences of the 16S rRNA gene (598-600 bp). The strains identified in our study (MF470200, MF470211) are most similar to A. phagocytophilum. Numbers at the branches show bootstrap support (1000 replicates). The scale-bar denotes distance 
mismatches/599 nucleotides), 96.7\% with A. centrale (19 or 20 mismatches/599 nucleotides), and $97.4 \%$ with $A$. ovis (15 or 16 mismatches/599 nucleotides), respectively.

To our knowledge, this is the first report of A. phagocytophilum in Père David's deer, a nationally protected species in China. There is little data on the pathogenic effects of $A$. phagocytophilum in deer although a wide variety are susceptible and some species can have prolonged infections and are most likely reservoir hosts [9]. Brown rat (Rattus norvegicus), black-striped field mouse (Apodemus agrarius), common pheasant (Phasianus colchicus) and Siberian thrush (Zoothera sibirica) that have been reported as hosts for A. phagocytophilum [10-12] are found to reside in DENNR. In domestic ruminants in Europe, however, infections are associated with fever and anorexia, abortion storms, occasional deaths, decreased milk production and immunosuppression [9]. Further studies are required to determine if the A. phagocytophilum infections we observed in the Père David's deer might be detrimental to the survival of the species.

Haemaphysalis longicornis is prevalent in the DENNR (summer: $89.5 \pm 17.1$ ticks $/ 10 \mathrm{~m}^{2}$, winter: $1.47 \pm 0.35$ ticks $/ 10 \mathrm{~m}^{2}$ ) and is the only reported tick species found on the Père David's deer in the reserve [4]. Although Ixodes persulcatus is usually associated with $A$. phagocytophilum in Asia, this tick is distributed in the north of China and, along with other ticks reported to be infected - Dermacentor silvarum, Ixodes ovatus, Ixodes niponensis, Haemaphsalis megaspinosa and Haemaphyslais douglasii - has not been reported in the DENNR reserve. Haemaphysalis longicornis has been found to be infected with A. phagocytophilum and A. bovis in China and other regions [13-16] and appears to be the most likely source of the infections identified in our study.

Humans can also be infected with $A$. phagocytophilum resulting in human granulocytic anaplasmosis which might be asymptomatic or a mild febrile illness with headache, malaise, and myalgia [17]. Uncommonly it might cause severe disease with multiple organ failure and death although mortality rates might be significantly higher in China (27\%) [18]. Our finding of infected deer and the reported high prevalence of $H$. longicornis which is known to feed on humans should alert health professionals to the possibility of $A$. phagocytophilum infections in patients with a history of visiting the DENNR.

To the best of our knowledge, this is the first report of A. phagocytophilum in Père David's deer. Further studies are needed to determine the effects on these infections on this endangered species and the role they might play in the epidemiology of human infections.

\section{Abbreviations}

DENNR: Dafeng Elk National Natural Reserve; FRET: fluorescence resonance energy transfer

\section{Acknowledgments}

Not applicable

\section{Funding}

This project was supported by the National High Technology Research and Development Program of China (2013AA102505-5), National Natural Science Foundation of China (31472067), Program granted for Scientific Innovation Research of College Graduate in Jiangsu province (KYZZ16_0496), the Excellent Doctoral Dissertation Scholarship of Yangzhou University and the Priority Academic Program Development of Jiangsu Higher Education Institutions.

\section{Availability of data and materials}

All data generated or analysed during this study are included in this published article. Representative sequences for 165 rRNA of A. phagocytophilum were submitted to the GenBank database under the accession numbers MF470200 and M470201.

\section{Authors' contributions}

CW, ZP and YY designed the study. YR and JL collected the samples. YY performed the experiment. CW and YY analyzed the data and wrote the manuscript. All authors read and approved the final version of the manuscript.

\section{Ethics approval}

The study protocol was reviewed and approved by the Institutional Animal Care and Use Committee of the Yangzhou University College of Veterinary Medicine.

\section{Consent for publication}

Not applicable.

\section{Competing interests}

The authors declare that they have no competing interests.

\section{Publisher's Note}

Springer Nature remains neutral with regard to jurisdictional claims in published maps and institutional affiliations.

\section{Author details}

${ }^{1}$ Jiangsu Co-innovation Center for the Prevention and Control of Important Animal Infectious Diseases and Zoonoses, Yangzhou University College of Veterinary Medicine, Yangzhou, Jiangsu, China. ${ }^{2}$ Yangzhou University College of Animal Science and Technology, Yangzhou, Jiangsu, China. ${ }^{3}$ Joint International Research Laboratory of Agriculture and Agri-Product Safety of Ministry of Education of China, Yangzhou University, Yangzhou, Jiangsu, China. ${ }^{4}$ Ross University School of Veterinary Medicine, Basseterre, Saint Kitts and Nevis. ${ }^{5}$ Dafeng Elk National Natural Reserve, Yancheng, Jiangsu, China. ${ }^{6}$ Department of Pathobiology, College of Veterinary Medicine, Auburn University, Auburn, AL, USA.

Received: 22 September 2017 Accepted: 17 December 2017

Published online: 08 January 2018

\section{References}

1. Ohtaishi N, Gao YT. A review of the distribution of all species of deer (Tragulidae, Moschidae, and Cervidae) in China. Mammal Rev. 1990;20:125-44.

2. Westmoreland LS, Stoskopf MK, Maggi RG. Prevalence of Anaplasma phagocytophilum in North Carolina eastern black bears (Ursus americanus). J Wildl Dis. 2016;52:968-70

3. Yang J, Liu Z, Niu Q, Luo J, Wang X, Yin H. Molecular detection of Anaplasma phagocytophilum in wild cervids and hares in China. J Wildl Dis. 2017;53:420-3.

4. Shen H, Ding YH, AH X, Ren YJ, Hou LB, Yuan GX. Haemaphysalis longicornis in captive and free-ranging Père David's deer (Elaphurus davidianus). Chinese J of Vet Parasitol. 2007:15(4):60-1.

5. Kelly PJ, Xu C, Lucas H, Loftis A, Abete J, Zeoli F, et al. Ehrlichiosis, babesiosis, anaplasmosis and hepatozoonosis in dogs from St. Kitts, West Indies. PLoS One. 2013;8:e53450.

6. Kawahara M, Rikihisa Y, Lin Q, Isogai E, Tahara K, Itagaki A, et al. Novel genetic variants of Anaplasma phagocytophilum, Anaplasma bovis, 
Anaplasma centrale, and a novel Ehrlichia sp. in wild deer and ticks on two major islands in Japan. Appl Environ Microbiol. 2006;72:1102-9.

7. Inokuma H, Ohno K, Onishi T, Raoult D, Brouqui P. Detection of ehrlichial infection by PCR in dogs from Yamaguchi and Okinawa prefectures, Japan. J Vet Med Sci. 2001;63:815-7.

8. Torina A, Agnone A, Blanda V, Alongi A, D'Agostino R, Caracappa S, et al, Development and validation of two PCR tests for the detection of and differentiation between Anaplasma ovis and Anaplasma marginale. Ticks Tick Borne Dis. 2012;3:283-7.

9. Dugat T, Lagrée AC, Maillard R, Boulouis HJ, Haddad N. Opening the black box of Anaplasma phagocytophilum diversity: current situation and future perspectives. Front Cell Infect Microbiol. 2015;5:61.

10. Stuen S, Granquist EG, Silaghi C. Anaplasma phagocytophilum - a widespread multi-host pathogen with highly adaptive strategies. Front Cell Infect Microbiol. 2013:3:31.

11. Yang J, Liu Z, Niu Q, Tian Z, Liu J, Guan G, et al. Tick-borne zoonotic pathogens in birds in Guangxi, Southwest China. Parasit Vectors. 2015;8:637.

12. Kang JG, Kim HC, Choi CY, Nam HY, Chae HY, Chong ST, et al. Molecular detection of Anaplasma, Bartonella, and Borrelia species in ticks collected from migratory birds from Hong-do Island, Republic of Korea. Vector Borne Zoonotic Dis. 2013;13:215-25.

13. Yaxue Z, Hongtao J, Qiuyue W, Zhixin F, Hongwei G, Pengpeng L, et al. Molecular detection of Anaplasma phagocytophilum in ixodid ticks in Hebei Province, China. Vector Borne Zoonotic Dis. 2011;11:1323-7.

14. Doan HT, Noh JH, Choe SE, Yoo MS, Kim YH, Reddy KE, et al. Molecular detection and phylogenetic analysis of Anaplasma bovis from Haemaphysalis longicornis feeding on grazing cattle in Korea. Vet Parasitol. 2013;196:478-81.

15. Wei F, Song M, Liu H, Wang B, Wang S, Wang Z, et al. Molecular detection and characterization of zoonotic and veterinary pathogens in ticks from northeastern China. Front Microbiol. 2016;7:1913.

16. Liu XY, Gong XY, Zheng C, Song QY, Chen T, Wang J, et al. Molecular epidemiological survey of bacterial and parasitic pathogens in hard ticks from eastern China. Acta Trop. 2017;167:26-30.

17. Li H, Zheng YC, Ma L, Jia N, Jiang BG, Jiang RR, et al. Human infection with a novel tick-borne Anaplasma species in China: a surveillance study. Lancet Infect Dis. 2015;15:663-70.

18. Li H, Zhou Y, Wang W, Guo D, Huang S, Jie S. The clinical characteristics and outcomes of patients with human granulocytic anaplasmosis in China. Int J Infect Dis. 2011;15:e859-66.

\section{Submit your next manuscript to BioMed Central and we will help you at every step:}

- We accept pre-submission inquiries

- Our selector tool helps you to find the most relevant journal

- We provide round the clock customer support

- Convenient online submission

- Thorough peer review

- Inclusion in PubMed and all major indexing services

- Maximum visibility for your research

Submit your manuscript at www.biomedcentral.com/submit

) Biomed Central 